Article

\title{
Isolation and Purification of a Hydrophobic Non-Ribosomal Peptide from an Escherichia coli Fermentation Broth
}

\author{
Arne Michael Oestreich ${ }^{1}$, Sebastian Reinhardt ${ }^{1}$, Doreen Gerlach ${ }^{2}$, Rong Fan ${ }^{1,2, *}$ and Peter Czermak ${ }^{1,3, *(1)}$ \\ 1 Institute of Bioprocess Engineering and Pharmaceutical Technology, University of Applied Sciences \\ Mittelhessen, Wiesenstraße 14, 35390 Giessen, Germany; arne.oestreich@lse.thm.de (A.M.O.); \\ sebastian-r-95@web.de (S.R.) \\ 2 Fraunhofer Institute for Molecular Biology and Applied Ecology (IME), Branch for Bioresources, \\ Ohlebergsweg 12, 35392 Giessen, Germany; doreen.gerlach@ime.fraunhofer.de \\ 3 Faculty of Biology and Chemistry, Justus-Liebig University of Giessen, Heinrich-Buff-Ring 17-19, \\ 35392 Giessen, Germany \\ * Correspondence: rong.fan@ime.fraunhofer.de (R.F.); peter.czermak@lse.thm.de (P.C.); \\ Tel.: +49-(0)-641-972-19312 (R.F.); +49-(0)-641-309-2551 (P.C.)
}

Citation: Oestreich, A.M.; Reinhardt, S.; Gerlach, D.; Fan, R.; Czermak, P. Isolation and Purification of a Hydrophobic Non-Ribosomal Peptide from an Escherichia coli Fermentation Broth. Separations 2021, 8, 241. https://doi.org/10.3390/ separations 8120241

Academic Editor: Alberto Cavazzini

Received: 4 November 2021

Accepted: 7 December 2021

Published: 9 December 2021

Publisher's Note: MDPI stays neutral with regard to jurisdictional claims in published maps and institutional affiliations.

Copyright: (c) 2021 by the authors. Licensee MDPI, Basel, Switzerland. This article is an open access article distributed under the terms and conditions of the Creative Commons Attribution (CC BY) license (https:// creativecommons.org/licenses/by/ $4.0 /)$.

\begin{abstract}
Non-ribosomal peptide synthases (NRPSs) generate versatile bioactive peptides by incorporating non-proteinogenic amino acids and catalyzing diverse modifications. Here, we developed an efficient downstream process for the capture, intermediate purification and polishing of a rhabdopeptide (RXP) produced by the NRPS VietABC. Many typical unit operations were unsuitable due to the similar physical and chemical properties of the RXP and related byproducts. However, we were able to capture the RXP from a fermentation broth using a hydrophobic resin (XAD-16N), resulting in a 14-fold increase in concentration while removing salts as well as polar and weak non-polar impurities. We then used ultra-high-performance liquid chromatography (UHPLC) for intermediate purification, with optimized parameters determined using statistical experimental designs, resulting in the complete removal of hydrophobic impurities. Finally, the UHPLC eluents were removed by evaporation. Our three-step downstream process achieved an overall product recovery of $81.7 \pm 8.4 \%$.
\end{abstract}

Keywords: Escherichia coli; downstream processing; microbial biotechnology; non-ribosomal peptide synthases; rhabdopeptide; ultra-high-performance liquid chromatography; design of experiments

\section{Introduction}

Non-ribosomal peptide synthases (NRPSs) catalyze the synthesis of versatile bioactive peptides that are suitable as lead compounds for the development of novel antibiotics, immunosuppressants and cytotoxic agents [1-8]. This broad product spectrum reflects the ability of NRPSs to incorporate non-proteinogenic amino acids and catalyze a variety of modifications [3,9]. We investigated an NRPS known as VietABC, which originates from the Gramnegative bacterium Xenorhabdus vietnamensis and produces a rhabdopeptide (RXP) [10]. RXPs are linear peptides, 2-8 amino acids in length with a terminal amine, which are exclusively found in entomopathogenic bacteria [10]. The RXP produced by VietABC consists of three $N$-methylated leucine residues and a C-terminal phenethylamine (Figure 1) [10]. However, various aromatic decarboxylated amino acids are accepted by the C-terminal condensation domain, with a hierarchy of phenethylamine $>$ tyramine $>$ tryptamine $[10,11]$. The purification of specific RXPs is complicated due to the broad spectrum of structurally similar products derived by a single NRPS.

The RXP is hydrophobic but lacks other physicochemical properties that can be used to separate it from similarly hydrophobic byproducts. $N$-methylation and C-terminal condensation with phenethylamine remove amphoteric properties that would allow separation by ion exchange chromatography; the RXP (502.73 Da) is also similar in size to byproducts, 
which rules out the use of size-exclusion chromatography. Finally, there is also no ligand available for affinity chromatography, and the addition of an affinity tag would be difficult because the RXP is synthesized without an RNA template. Thus, the hydrophobic property of the RXP seemed to be a reasonable starting point for capturing this molecule.

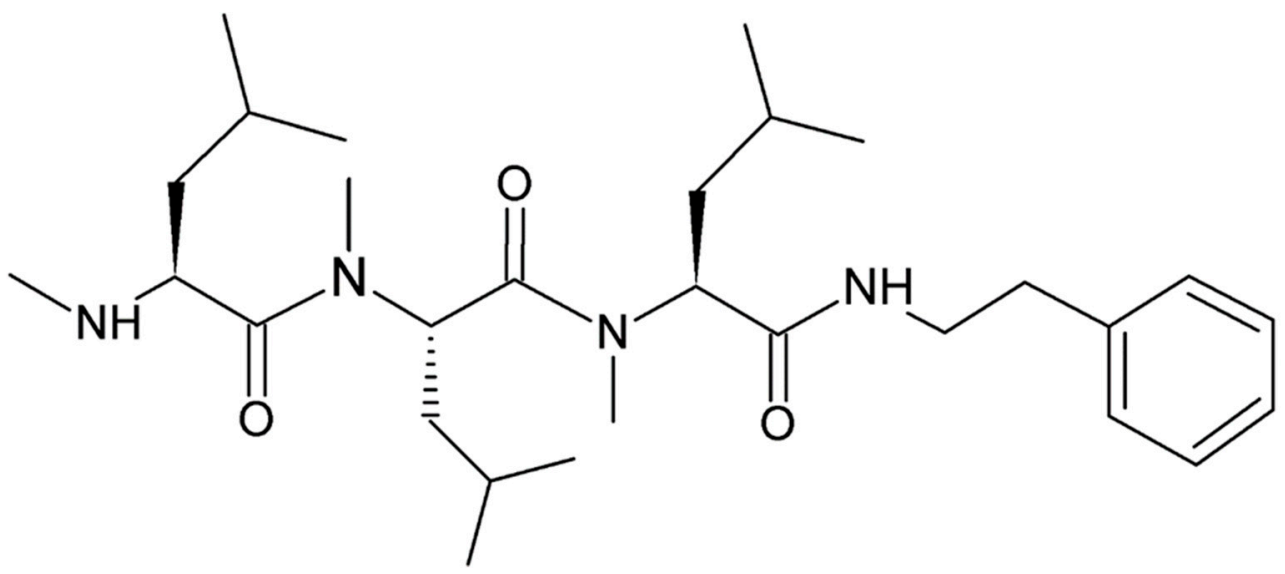

Figure 1. Structure of the rhabdopeptide produced by VietABC, consisting of three $N$-methylated L-leucine residues and the C-terminal condensed phenethylamine [10].

Amberlite XAD-16N is a polystyrene divinyl benzene resin widely used for the removal of hydrophobic substances from polar solvents and aqueous solutions [12-18]. The porous beads have a specific surface area of $\sim 800 \mathrm{~m}^{2} \mathrm{~g}^{-1}[17,18]$, providing a high capacity to adsorb hydrophobic substances. Amberlite XAD-16N is a cost-effective adsorbent for capture steps because it can be regenerated by being rinsed with common non-polar solvents. This resin has already proven to be suitable for the removal of RXPs from fermentation broths [10], but it is unclear whether its selectivity would be sufficient to achieve a high degree of purification. Another process option that exploits the hydrophobicity of the RXP but offers high selectivity is reversed-phase high-performance liquid chromatography (RP-HPLC). This technique is widely used for analytical applications $[10,19]$ and also has the potential to be used as a preparative step. Here, we tested a combination of capture chromatography using XAD-16N resin followed by RP-HPLC to optimize the recovery of the RXP from an Escherichia coli fermentation broth.

\section{Materials and Methods}

\subsection{Production Strain and Vectors}

The RXP was synthesized using an E. coli DH10B strain carrying two plasmids: pCX71, providing the biosynthetic gene cluster encoding VietABC, and pACYC, providing the $m t a A$ gene encoding phosphopantetheinyl transferase. The bacterial strain was kindly provided by Prof. Dr. Helge B. Bode (Institute for Molecular biosciences, Goethe University Frankfurt, Frankfurt, Germany).

\subsection{Culture Medium}

We used a chemically defined medium as previously described [19], but modified to contain $1.25 \mathrm{mM}$ L-leucine, $15.3 \mathrm{mM}$ ammonium chloride and $102 \mathrm{mM}$ disodium succinate. The detailed media composition can be found in the Supplementary Materials.

\subsection{Reactor Cultivation}

RXP biosynthesis was carried out in a Labfors 3 stirred-tank reactor (Inforce, Bottmingen, Switzerland) with a working volume of $5 \mathrm{~L}$, equipped with $\mathrm{pH}$, dissolved oxygen and temperature sensors. The reactor was filled to $\sim 4.3 \mathrm{~L}$ with the inorganic components of the medium $\left(\mathrm{NH}_{4} \mathrm{Cl}, \mathrm{NaCl}, \mathrm{Na}_{2} \mathrm{HPO}_{4}\right.$ and $\left.\mathrm{KH}_{2} \mathrm{PO}_{4}\right)$ and was autoclaved at $121{ }^{\circ} \mathrm{C}$ for $20 \mathrm{~min}$ before the remaining pre-sterilized components were added with a syringe. Aeration was provided by compressed air introduced via a gassing pipe at $1 \mathrm{vvm}$ and a 
stirrer speed of $500 \mathrm{rpm}$. Dissolved oxygen partial pressure was controlled at $30 \%$ of the saturation concentration by increasing the stirrer speed (500-575 rpm). The fermentation was initiated at an optical density ( $\triangle \mathrm{OD} 600)$ of $0.05,30^{\circ} \mathrm{C}$ and a pH of 7.0 (maintained by adding $2 \mathrm{M}$ hydrochloric acid). The process was stopped after $72 \mathrm{~h}$ when the culture reached the stationary phase.

\subsection{Cell Disruption}

The fermentation broth was centrifuged at $16,100 \times g$ for $20 \mathrm{~min}$ at $4{ }^{\circ} \mathrm{C}$ and the cell pellet was resuspended in $0.9 \% \mathrm{NaCl}\left(\mathrm{W}_{\text {isotonic saline }} / \mathrm{W}_{\text {cells }}=4.75\right)$. The intracellular product was released by cell disruption using an EmulsiFlex-C5 high-pressure homogenizer (AVESTIN, Ottawa, ON, Canada). The cells were disrupted at 1500 bar and the homogenate was stored on ice. This process was repeated to ensure that most cells were disrupted, as confirmed by light microscopy.

\subsection{RXP Quantification}

RXP was quantified by UHPLC on an Ultimate 3000 device equipped with a Dionex Corona Veo RS detector (Thermo Fisher Scientific, Dreieich, Germany) and a UPLC BEH C18 column (130 ̊, $1.7 \mu \mathrm{m}, 2.1 \mathrm{~mm} \times 100 \mathrm{~mm}$ ) (Waters, Eschborn, Germany). The process was calibrated using standards produced by solid-phase synthesis and verified by mass spectrometry, kindly provided by Prof. Dr. Helge B. Bode. Samples were separated at a flow rate of $0.4 \mathrm{~mL} \mathrm{~min}^{-1}$ using acetonitrile (Merck, Darmstadt, Germany) and ultrapure water containing $1 \%(v / v)$ formic acid as eluents. The process was initiated with $5 \%(v / v)$ acetonitrile held for $3 \mathrm{~min}$ before a linear increase to $30 \%(v / v)$ acetonitrile in $0.8 \mathrm{~min}$, then to $55 \%(v / v)$ acetonitrile in $7.2 \mathrm{~min}$ and to $95 \%(v / v)$ acetonitrile in $1 \mathrm{~min}$. After being held at $95 \%(v / v)$ acetonitrile for $4 \mathrm{~min}$, the acetonitrile concentration was reduced to $5 \%(v / v)$ in $1 \mathrm{~min}$, followed by a re-equilibration at $5 \%(v / v)$ acetonitrile for $3 \mathrm{~min}$. The temperature was held at $40{ }^{\circ} \mathrm{C}$ throughout. The flow state was switched off for the first 3 min to avoid ions entering the detector. The samples were centrifuged at $16,100 \times g$ for $20 \mathrm{~min}$ at $20{ }^{\circ} \mathrm{C}$ and then transferred to glass vials for analysis.

\subsection{Succinate Quantification}

Succinate was quantified using a 1100 Series HPLC (Agilent Technologies, Santa Clara, CA, USA) fitted with a 1260 Infinity refractive index detector (Agilent Technologies, Santa Clara, CA, USA) and an Aminex HPX-87H Column (Bio-Rad Laboratories, Hercules, CA, USA). Isocratic analysis was carried out at $65^{\circ} \mathrm{C}$ at a flow rate of $0.6 \mathrm{~mL} \mathrm{~min}{ }^{-1}$ with ultrapure water containing $5 \mathrm{mM}$ sulfuric acid. Carrez precipitation was applied to the fermentation broth supernatant followed by centrifugation at $16,100 \times g$ for $20 \mathrm{~min}$ at $20^{\circ} \mathrm{C}$. The supernatant was passed through a $0.2 \mu \mathrm{m}$ nylon filter and transferred to glass vials.

\subsection{Measurement of Cell Dry Weight}

Cell density was measured using a BioSpectrometer basic (Eppendorf, Hamburg, Germany) at $600 \mathrm{~nm}$ within the $\Delta$ OD600 range 0.05-0.3. Samples with a higher $\Delta$ OD600 value were diluted with $0.9 \% \mathrm{NaCl}$. An experimentally established correlation with the $\triangle \mathrm{OD} 600$ was used to calculate the cell dry weight (CDW).

\subsection{Capture Step}

The RXP was captured by fast protein liquid chromatography (FPLC) using an NGC Discover 10 Pro Chromatography System with ChromLab software (Bio-Rad Laboratories, Hercules, CA, USA). We loaded $1 \mathrm{~mL}$ PureCube Compact Cartridges (Cube Biotech, Wayne, PA, USA) with Amberlite XAD-16N and stored them in $20 \mathrm{mM}$ sodium acetate and $20 \%$ $(v / v)$ ethanol in ultrapure water. The column was washed with 5 column volumes $(\mathrm{CV})$ of ultrapure water and equilibrated with $10 \mathrm{CV}$ of $20 \mathrm{mM}$ sodium acetate at $1 \mathrm{~mL} \mathrm{~min}{ }^{-1}$. The

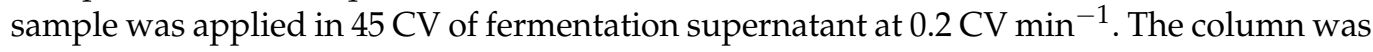
washed with $10 \mathrm{CV} 20 \mathrm{mM}$ sodium acetate followed by an increase in ethanol concentration 
from $0 \%$ to $99.8 \%$ in $50 \mathrm{CV}$ at $1 \mathrm{CV}$ min $^{-1}$. The $\mathrm{XAD}-16 \mathrm{~N}$ was regenerated with $5 \mathrm{CV}$ of

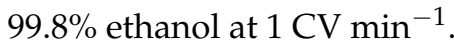

\subsection{Experimental Designs for Intermediate Purification}

Preparative UHPLC was used for the separation of strong hydrophobic impurities. A randomized quadratic response surface methodology design (I-optimal) was established to enhance the resolution of the UHPLC method using Design Expert v11 (Stat-Ease, Minneapolis, MN, USA). Table 1 shows the experimental design. The preparative UHPLC method was similar to the analytical method, but a single gradient of $5-95 \%(v / v)$ acetonitrile was applied. For method development, the pre-purified capture-step faction was diluted 1:10 with ethanol due to the high concentration. The factor ranges were set to $0.2-1 \%(v / v)$ formic acid, $0.5-4.5 \% \mathrm{~min}^{-1}$ slope of the acetonitrile gradient and $30-50{ }^{\circ} \mathrm{C}$ for the temperature. The fraction containing the RXP was collected manually, based on the UV signal.

Table 1. Influence and response factors of the experimental design for intermediate purification by UHPLC.

\begin{tabular}{|c|c|c|c|c|}
\hline Run & $X_{1}$ : Formic Acid (\%) & $X_{2}:$ Gradient Slope $\left(\% \min ^{-1}\right)$ & $\mathrm{X}_{3}:$ Temperature $\left({ }^{\circ} \mathrm{C}\right)$ & Resolution \\
\hline 1 & 0.6 & 2.5 & 40 & 1.56 \\
\hline 2 & 0.2 & 1.5 & 45 & 1.21 \\
\hline 3 & 1 & 2.5 & 30 & 1.67 \\
\hline 4 & 1 & 4.5 & 35 & 1.19 \\
\hline 5 & 0.6 & 4.5 & 50 & 1.07 \\
\hline 6 & 0.2 & 2.5 & 35 & 1.02 \\
\hline 7 & 0.2 & 4.5 & 30 & 0.95 \\
\hline 8 & 0.4 & 0.5 & 50 & 1.95 \\
\hline 9 & 0,6 & 2.5 & 40 & 1.57 \\
\hline 10 & 0.2 & 0.5 & 35 & 1.56 \\
\hline 11 & 1 & 2.5 & 50 & 1.55 \\
\hline 12 & 0.6 & 4.5 & 50 & 1.00 \\
\hline 13 & 0.4 & 0.5 & 50 & 1.81 \\
\hline 14 & 1 & 2.5 & 50 & 1.59 \\
\hline 15 & 1 & 0.5 & 40 & 2.03 \\
\hline 16 & 0.8 & 1.5 & 45 & 1.76 \\
\hline 17 & 0.6 & 0.5 & 30 & - \\
\hline 18 & 0.8 & 1.5 & 35 & 1.75 \\
\hline 19 & 0.6 & 2.5 & 40 & 1.54 \\
\hline 20 & 0.6 & 2.5 & 40 & 1.62 \\
\hline 21 & 0.6 & 3.5 & 30 & 1.26 \\
\hline 22 & 0.2 & 3.5 & 50 & 0.99 \\
\hline 23 & 1 & 4.5 & 35 & 1.35 \\
\hline
\end{tabular}

\subsection{Polishing}

The UHPLC fractions from intermediate purification were collected and transferred to glass vials, and the eluents were evaporated using a SAVANT SPD1010 SpeedVac concentrator (Thermo Fisher Scientific, Dreieich, Germany) at $40{ }^{\circ} \mathrm{C}$. The product was re-dissolved in ultrapure water.

\section{Results and Discussion}

\subsection{Upstream Processing}

The cells were cultivated for $72 \mathrm{~h}$, yielding $92.9 \mathrm{mg} \mathrm{L}^{-1}$ of the RXP from a CDW of $1.7 \mathrm{~g} \mathrm{~L}^{-1}$ (Figure 2). Fermentation was stopped when the dissolved oxygen concentration exceeded $90 \%$ of the saturation concentration. The RXP concentration was lower than the optimized process previously described [19], caused by the altered medium composition and process parameters. However, the RXP concentration was in agreement with the statistical designs established in this work [19]. 

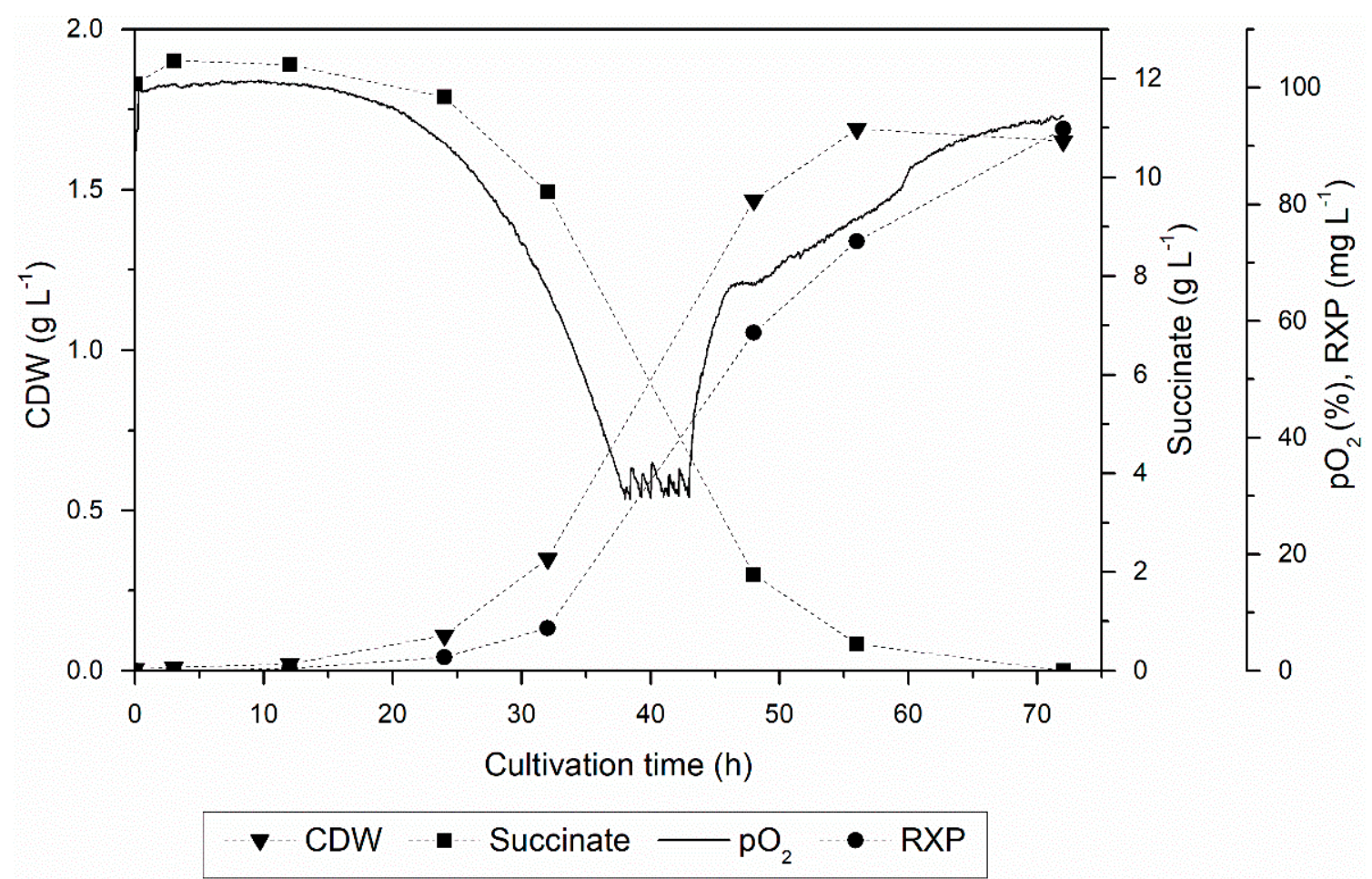

Figure 2. Kinetic profile of RXP production, showing CDW, succinate concentration, RXP concentration and oxygen partial pressure in a $5 \mathrm{~L}$ batch process.

\subsection{Product Localization}

The proportion of the total product mass secreted to the supernatant was $99.70 \%$, whereas only $0.30 \%$ remained in the cell lysate. Accordingly, we decided that cell disruption was an unnecessary and economically unfavorable process step.

\subsection{Product Analysis}

VietABC produces an RXP consisting of three $N$-methylated L-leucine residues and a C-terminal phenethylamine [10]. However, UHPLC analysis of the fermentation broth supernatant revealed multiple byproducts as smaller peaks close to the main RXP peak (Figure 3). None of the peaks (including the main RXP peak) were detected when E. coli DH10B was cultivated without or with only one of the two plasmids, even though arabinose was used for induction (data not shown). NRPSs were found to have a relaxed methyl transferase activity [10], and we therefore speculated that the byproducts are derivatives of the RXP lacking one or more $N$-methyl groups.

\subsection{Product Capture}

Methanol is widely used for the elution of hydrophobic substances from XAD-16N resin [10]. However, methanol is a toxic and volatile solvent, so we investigated the use of ethanol for eluting the RXP from the adsorbent in the capturing step.

Increasing the ethanol concentration immediately led to a broad peak with a maximum at $\sim 20 \%$ ethanol, followed by another peak at $\sim 50 \%$ ethanol and a shoulder at $~ 100 \%$ ethanol (Figure 4). The three peaks were detected at both $\sim 220 \mathrm{~nm}$, which represents peptide bonds [20,21], and $\sim 280 \mathrm{~nm}$, which represents the aromatic groups of phenylalanine, tryptophan and tyrosine [20,22]. The influence of $\mathrm{N}$-methylation on the absorption characteristics of the product was unknown, but we anticipated a signal at $220 \mathrm{~nm}$ due to the presence of peptide bonds in the RXP as well as a signal at $280 \mathrm{~nm}$ because the RXP contains the aromatic residue phenethylamine (a decarboxylated derivative of phenylalanine). The chromatogram indicated the elution of hydrophobic impurities later than RXP, suggesting that it may be possible to purify the RXP via preparative chromatography. We therefore 
tested combinations of different step gradients to remove the hydrophobic impurities while maximizing the concentration of the RXP.

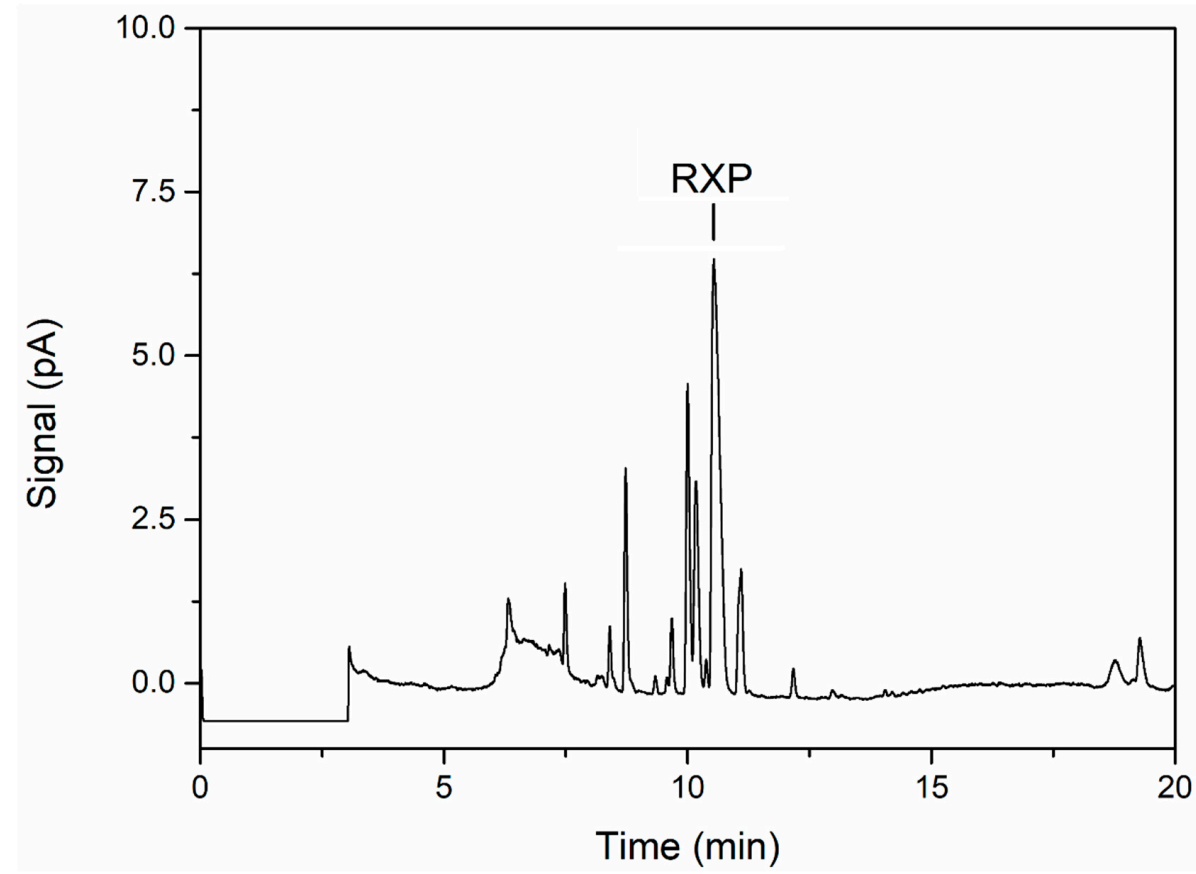

Figure 3. UHPLC chromatogram of the fermentation supernatant showing the main product (RXP) and byproducts (three peaks to the left of RXP) of VietABC.

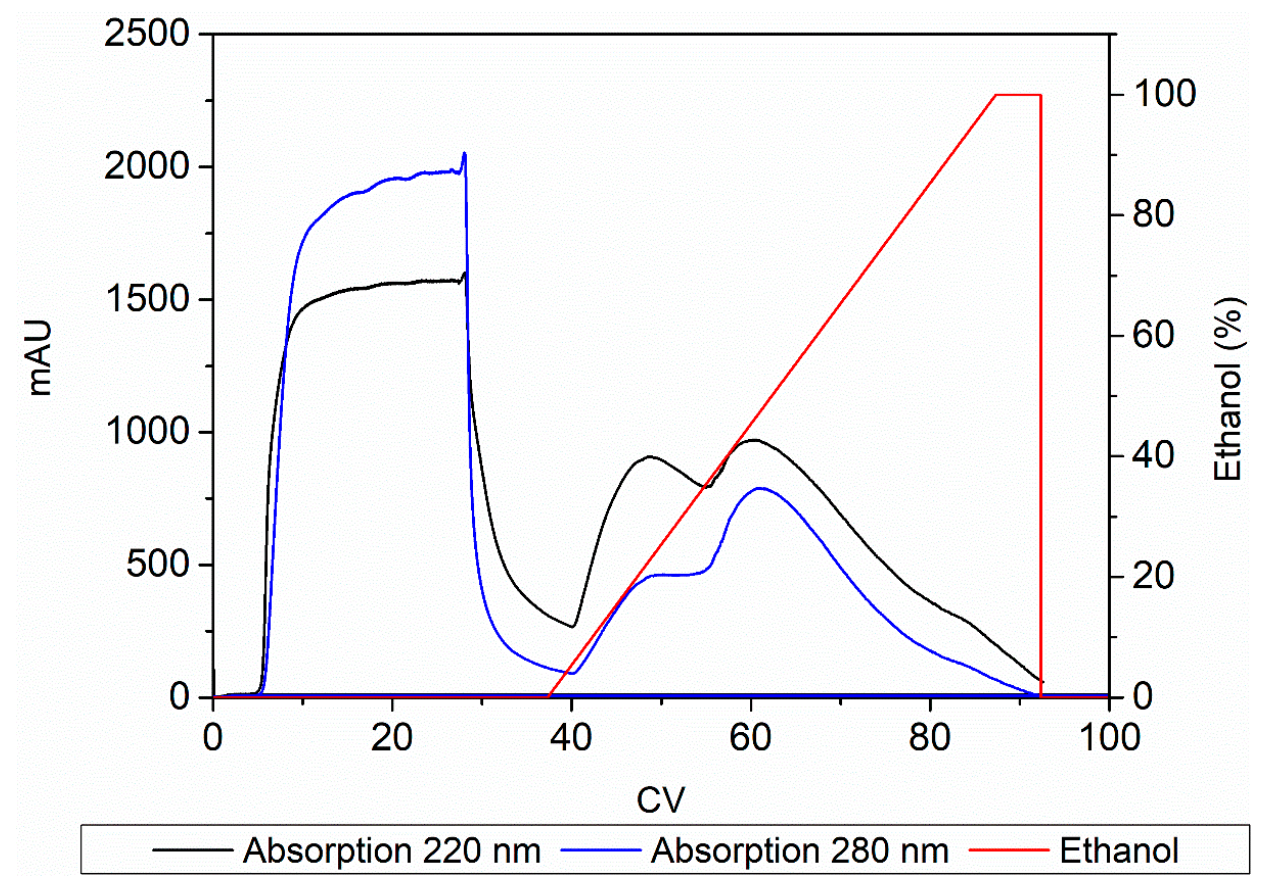

Figure 4. FPLC chromatogram showing absorption signals at 220 and $280 \mathrm{~nm}$ spanning the linear elution gradient of ethanol.

Figure $5 \mathrm{~A}$ shows that product elution begins at an ethanol concentration of $\sim 40 \%$ in a linear gradient. Accordingly, the first peak of the UV chromatogram in Figure 4 consists of weakly hydrophobic substances that can be separated from the product. However, the linear ethanol gradient diluted the RXP; $30 \mathrm{CVs}$ were required to collect all the product. Applying a step gradient (Figure $5 \mathrm{~B}$ ) resulted in the separation of the weakly hydrophobic 
impurities at an ethanol concentration of $20 \%$ without a loss of the RXP, as confirmed by UHPLC analysis. An ethanol concentration of 50\% was insufficient to elute the RXP completely, and much of it was recovered during the regeneration step with $100 \%$ ethanol. UHPLC analysis also showed that the remaining strong hydrophobic impurities were not separated from the RXP (data not shown). Nevertheless, by applying the step gradient we increased the product concentration by $\sim$ four-fold. No further improvement was achieved by increasing the ethanol concentration in the elution step to $75 \%$, and the product was again recovered during the regeneration step (Figure 5C). Given the inability to remove the strong hydrophobic impurities, we omitted the third step and eluted the product with $100 \%$ ethanol after removing the weak hydrophobic impurities at 20\% ethanol (Figure 5D). This achieved a six-fold increase in the RXP concentration; most of the product was collected in $\sim 10 \mathrm{CVs}$, thus reducing the consumption of eluents and shortening the process time compared to the linear gradient. To intensify this process, we investigated the degree to which the RXP can be eluted completely from the adsorbent with ethanol before the thermodynamic equilibrium shifts toward adsorption.

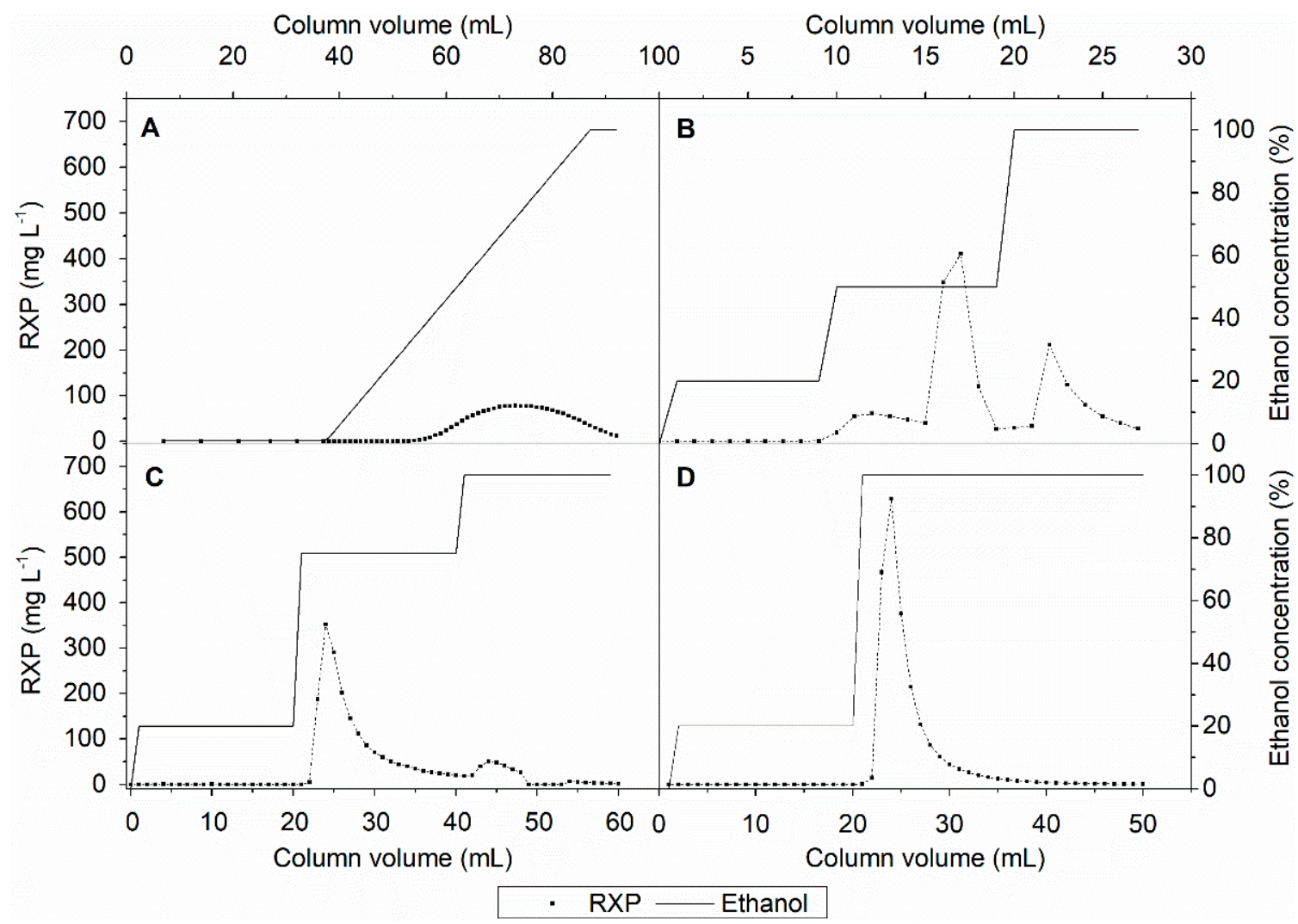

Figure 5. Intermediate purification of the RXP. (A) Elution profile of a linear ethanol gradient. (B) Elution profile of a step gradient with $20 \%, 50 \%$ and $100 \%$ ethanol. (C) Elution profile of a step gradient with $20 \%, 75 \%$ and $100 \%$ ethanol. (D) Elution profile of a step gradient with $20 \%$ and $100 \%$ ethanol.

The maximum RXP concentration that could be eluted without loss from XAD$16 \mathrm{~N}$ using ethanol, including the remaining hydrophobic impurities, was approximately $2000 \mathrm{mg} \mathrm{L}^{-1}$, as shown by the linear regression of Figure 6. Based on these results, $800 \mathrm{~mL}$ of the fermentation supernatant was processed in a $5 \mathrm{~mL}$ column packed with XAD-16N, with a target RXP concentration of $\sim 1500 \mathrm{mg} \mathrm{L}^{-1}$. 


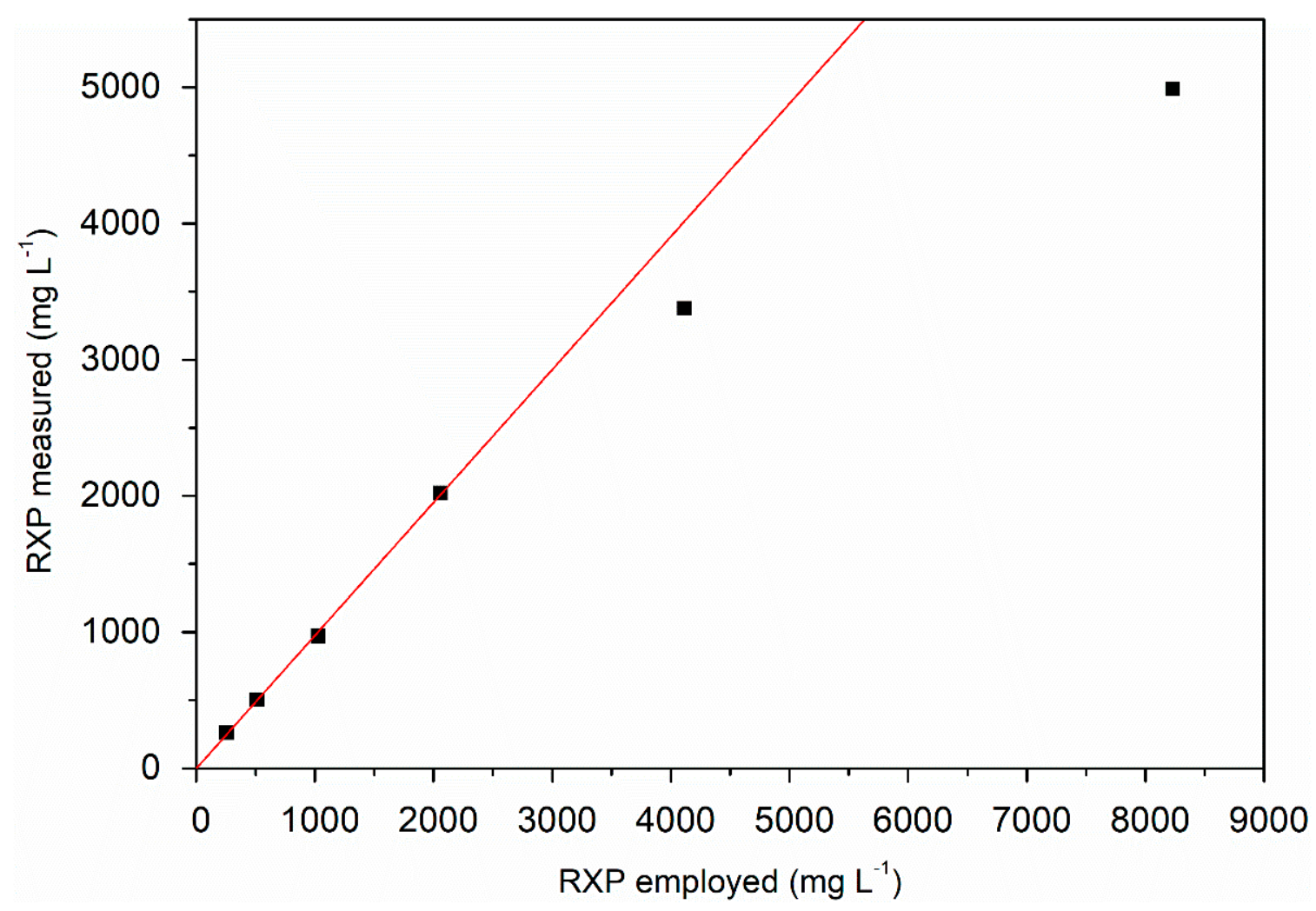

Figure 6. Maximum RXP concentration eluted completely from XAD-16N resin when using ethanol at $30^{\circ} \mathrm{C}$ with the linear correlation (red regression line) of the employed RXP and the measured RXP after elution.

Table 2 shows that the RXP was found in the flow through and wash fractions. The reduced efficiency of adsorption may reflect a dead space or channel formation caused by column scale-up. Notwithstanding the above, we achieved a recovery of $91.9 \pm 1.6 \%$ along with a $\sim 14$-fold increase in product concentration.

Table 2. RXP capture from $800 \mathrm{~mL}$ fermentation supernatant in a $5 \mathrm{~mL}$ column packed with XAD- $16 \mathrm{~N}$ resin at $30^{\circ} \mathrm{C}$.

\begin{tabular}{cccc}
\hline & RXP Concentration $\left.\mathbf{m g ~ L}^{-1}\right)$ & Volume $(\mathbf{m L})$ & RXP Mass (mg) \\
\hline Supernatant & $92.90 \pm 0.52$ & 800 & $74.32 \pm 0.42$ \\
Flow through & $4.34 \pm 0.19$ & 800 & $3.47 \pm 0.15$ \\
20\% ethanol wash fraction & $5.50 \pm 0.18$ & 105.5 & $0.58 \pm 0.02$ \\
$100 \%$ ethanol elution & $1369.18 \pm 23.79$ & 48.6 & $68.31 \pm 1.16$ \\
\hline
\end{tabular}

\subsection{Experimental Design for Intermediate Purification}

We set up a two-level factorial screening with temperature, formic acid concentration $(\mathrm{pH})$ and gradient slope as potential influence factors, and used this to determine the most significant influence factors affecting the resolution of the RXP and the byproducts of VietABC with the lowest difference in retention time. We found that all three factors had a significant effect on the resolution (Supplementary Materials). The optimization of HPLC methods often involves the evaluation of $\mathrm{pH}$ [23-27] and temperature [23,28-31]. The temperature affects viscosity [28] as well as hydrophobic interactions by influencing enthalpy and entropy [32,33]. The design space limits for the optimization of the resolution were determined within the screening (gradient slope) or were based on parameters affecting either the stability of the RXP or the equipment (temperature and formic acid concentration). The lower gradient slope was set to $0.5 \% \mathrm{~min}^{-1}$ to avoid an excessive process duration and the upper limit of $4.5 \% \mathrm{~min}^{-1}$ was set close to the center point of the screening. The lower temperature limit was set to $30^{\circ} \mathrm{C}$ to avoid pressures $>800$ bar. Peptides and proteins are sensitive to heat denaturation, which can affect higher-order 
structures $[34,35]$. The RXP has a linear structure and is therefore less heat-sensitive, so $50{ }^{\circ} \mathrm{C}$ was set as the upper temperature limit. The upper formic acid concentration limit was set to $1 \%(v / v)$ to avoid a $\mathrm{pH}$ of $<2$ in the aqueous phase.

The response value of run 17 was ignored due to overlapping peaks, resulting in a distorted resolution. The design showed a homogenous distribution of externally studentized residuals, indicating that no transformation was required. All influence factors used to generate the model were significant $(p$-value $<0.05)$ except the temperature variable $(p$-value $=0.7874)$, as shown in Table 3. A $p$-value lower than 0.05 indicates that the null hypothesis (a factor has no effect) is rejected. Nevertheless, temperature was added to the design to maintain the hierarchical model arrangement due to the significant interaction with the gradient slope. A non-significant lack of fit $(p$-value $=0.1123)$ indicates that the model is sufficient for prediction within the design space.

Table 3. Analysis of variance (ANOVA) of the reduced quadratic resolution model, using the coding $\mathrm{X}_{1}=$ formic acid concentration $(\mathrm{v} / \mathrm{v})(\%), \mathrm{X}_{2}=$ gradient slope $\left(\% \mathrm{~min}^{-1}\right)$ and $\mathrm{X}_{3}=$ temperature $\left({ }^{\circ} \mathrm{C}\right)$.

\begin{tabular}{cccccc}
\hline Source & Sum of Squares & df & Mean Square & $\boldsymbol{F}$-Value & $\boldsymbol{p}$-Value \\
\hline Model & 2.0933 & 5 & 0.4187 & 52.8973 & $<0.0001$ \\
$\mathrm{X}_{1}$ & 0.6121 & 1 & 0.6121 & 77.3328 & $<0.0001$ \\
$\mathrm{X}_{2}$ & 1.3689 & 1 & 1.3689 & 172.9577 & $<0.0001$ \\
$\mathrm{X}_{3}$ & 0.0006 & 1 & 0.0006 & 0.0752 & 0.7874 \\
$\mathrm{X}_{2 \times 3}$ & 0.0435 & 1 & 0.0435 & 5.5014 & 0.0322 \\
$\mathrm{X}_{1}^{2}$ & 0.1052 & 1 & 0.1052 & 13.2963 & 0.0022 \\
Residual & 0.1266 & 16 & 0.0079 & & \\
Lack of fit & 0.0973 & 9 & 0.0108 & 2.5809 & 0.1123 \\
Pure error & 0.0293 & 7 & 0.0042 & & \\
Total & 2.2199 & 21 & & & \\
\hline
\end{tabular}

Increasing the formic acid concentration improved the resolution within the design space limits, as indicated by the positive coefficient estimate (Table 4). The negative coefficient estimate of the gradient slope showed that a gradual increase in the acetonitrile concentration leads to a higher resolution compared to a progressive increase. The slope of the acetonitrile gradient and the formic acid concentration showed the strongest influence on resolution, whereas temperature had only a minor impact, as indicated by the coefficients estimate. However, the interaction between the temperature and gradient slope was $\sim 10$-fold higher than the linear influence of the temperature. The effect of the temperature at a gradient slope of $0.5 \% \mathrm{~min}^{-1}$ was positive, even though the related coefficient estimates were negative due to the interaction between these variables (Figure 7). The only quadratic effect was the formic acid concentration. The actual equation for prediction obtained by the model is shown in Equation (1) below:

$$
\mathrm{Y}=0.9100+1.7223 \mathrm{X}_{1}-0.0148 \mathrm{X}_{2}+0.0104 \mathrm{X}_{3}-0.0045 \mathrm{X}_{2} \mathrm{X}_{3}-0.9584 \mathrm{X}_{1}^{2}
$$

Table 4. Coefficients in terms of coded factors of the reduced quadratic resolution model, with coded factors $\mathrm{X}_{1}=$ formic acid concentration $(v / v)(\%), \mathrm{X}_{2}=$ gradient slope $\left(\% \min ^{-1}\right)$ and $\mathrm{X}_{3}=$ temperature $\left({ }^{\circ} \mathrm{C}\right)$.

\begin{tabular}{cccc}
\hline Factor & Coefficient Estimate & df & Error \\
\hline Intercept & 1.5303 & 1 & 0.0303 \\
$\mathrm{X}_{1}$ & 0.2289 & 1 & 0.0260 \\
$\mathrm{X}_{2}$ & -0.3867 & 1 & 0.0294 \\
$\mathrm{X}_{3}$ & -0.0077 & 1 & 0.0282 \\
$\mathrm{X}_{2} \mathrm{X}_{3}$ & -0.0893 & 1 & 0.0381 \\
$\mathrm{X}_{1}{ }^{2}$ & -0.1533 & 1 & 0.0421 \\
\hline
\end{tabular}



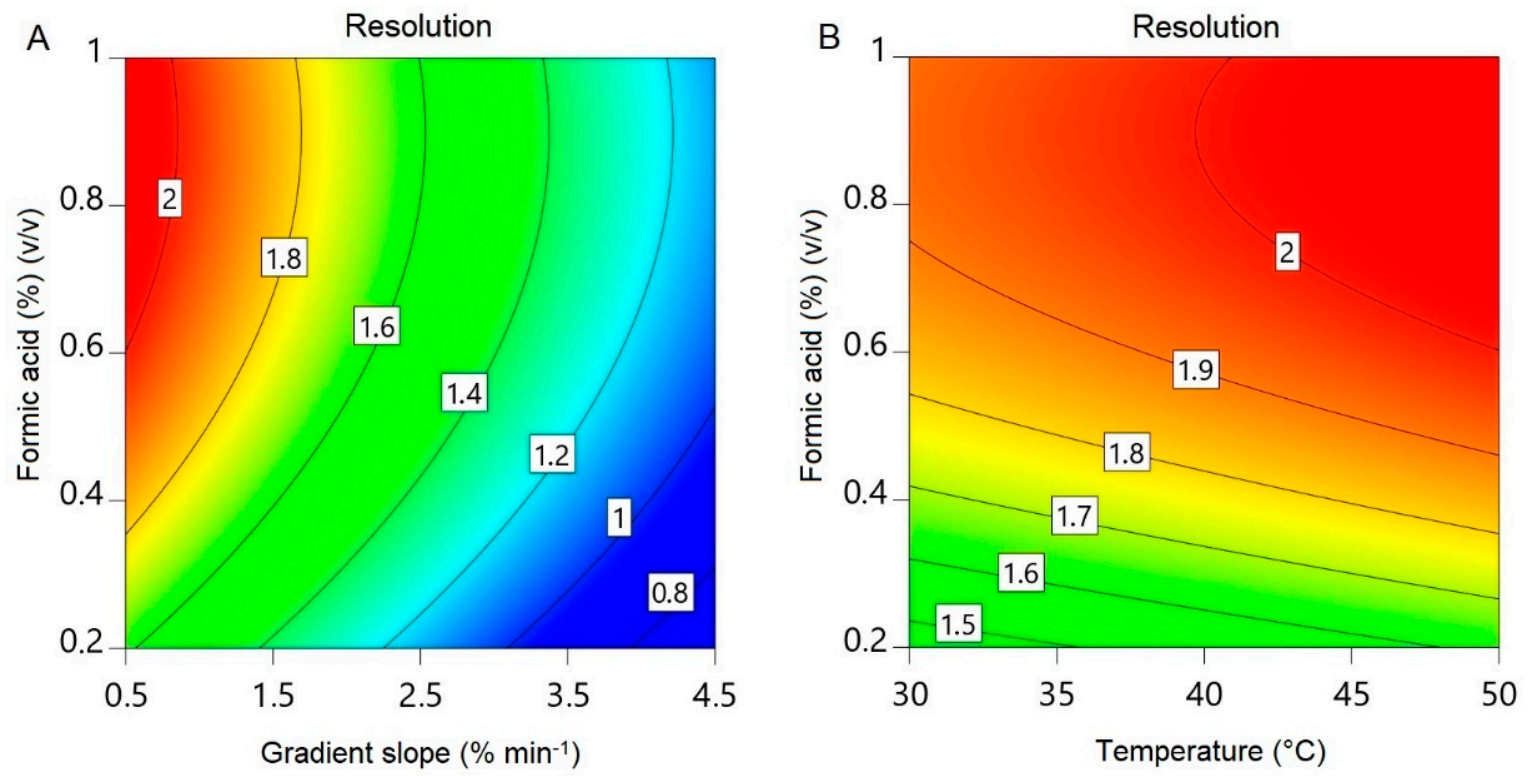

Figure 7. Contour plots of the reduced quadratic resolution model. (A) Formic acid concentration and gradient slope at $50{ }^{\circ} \mathrm{C}$. (B) Formic acid concentration and temperature at a gradient slope of $0.5 \% \mathrm{~min}^{-1}$.

The coefficient of determination $\left(R^{2}=0.9430\right)$ indicated that less than $5.7 \%$ of the variance could not be described by the model. The small difference between the coefficient of determination and the adjusted coefficient of determination (adjusted $R^{2}=0.9251$ ) implies that the model did not suffer negative bias following the addition of more terms (e.g., the non-significant temperature variable). Furthermore, the adjusted coefficient of determination and the predicted coefficient of determination (predicted $R^{2}=0.8819$ ) were in reasonable agreement; the model had a sufficient signal-to-noise ratio (adequate precision $=24.4114$ ).

The resolution ranged from $<0.8$ to $>2$ within the design space (Figure 7). A resolution $>1.5$ is desired for the baseline separation of two substances [36]. A higher value would increase the amount of the RXP that can be purified during a single UHPLC run. The design does not cover the optima for the temperature and gradient slope caused by the linear effect of these factors. This is a result of the design space limits based on the RXP stability and equipment concerns. A wider temperature limit could have covered the optimum for this factor but may result in product degradation, while further reduction of the gradient slope would probably have continued to have a linear effect on resolution. Confirmation runs were therefore carried out at $1 \%(v / v)$ formic acid, $50{ }^{\circ} \mathrm{C}$ and a gradient slope of $0.5 \% \mathrm{~min}^{-1}$, resulting in a resolution of $2.36 \pm 0.02$ (Figure 8). This exceeds the $95 \%$ confidence interval for the mean (1.94-2.21) but lies within the 95\% tolerance interval for $99 \%$ of the population (1.64-2.51). This high resolution allowed us to collect the entire peak in one fraction, leading to a recovery of $95.9 \pm 4.9 \%$. The drawbacks of the shallow gradient slope are the long time needed for a single run and the consumption of eluents. This can be overcome by a progressive increase in the gradient at the beginning of a run, followed by a shallow gradient during the separation of the RXP from the impurities and finally a step increase in the acetonitrile concentration for column regeneration after RXP elution. Column length, mobile-phase velocity, particle size and pore size are further points to improve the resolution by affecting theoretical plate counts [37,38]. The number of theoretical plates is given by the quotient of the column length and plate height [37], and therefore increases in theory proportionally with column length. Mobile-phase velocity, particle diameter and porosity affect plate height [37,38], resulting in a higher plate count for a constant column length. Optimizing these parameters could achieve a resolution sufficient to purify the undiluted sample of the capture fraction. Additionally, the inner diameter of the column affects the injection volume and therefore the maximum product mass that can be purified during a single run of HPLC. Commercial systems with an inner 
column diameter of more than a meter are available that could purify the RXP at least in a two digit gram scale during a single run.

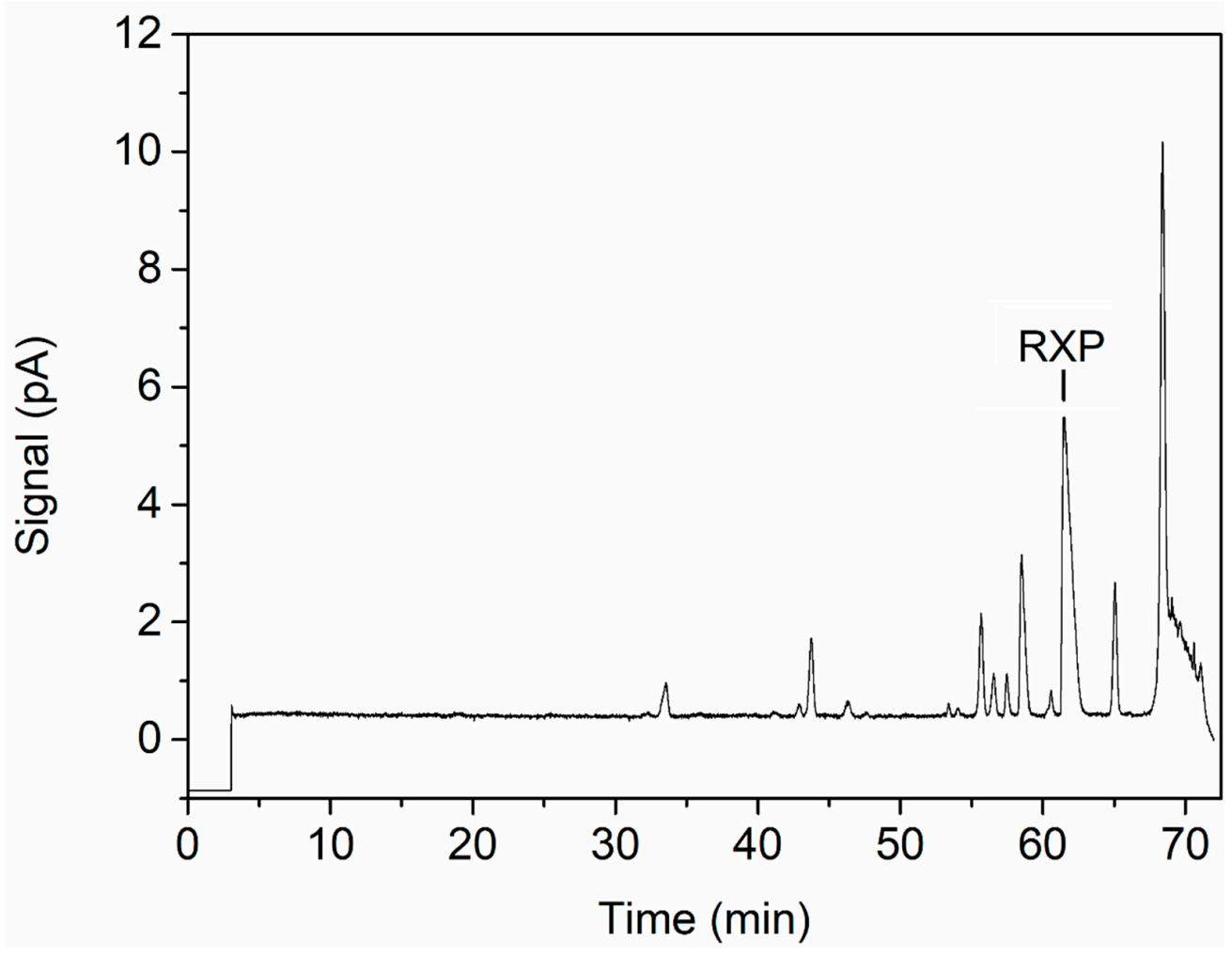

Figure 8. UHPLC chromatogram of the optimized method $\left(1 \%(v / v)\right.$ formic acid, $50{ }^{\circ} \mathrm{C}$ and a gradient slope of $\left.0.5 \% \mathrm{~min}^{-1}\right)$, showing the RXP and separated byproducts of VietABC.

\subsection{Polishing}

The eluents of the intermediate purification fraction containing the RXP were evaporated completely and the solid residue was re-dissolved in ultrapure water, achieving a recovery of $92.7 \pm 7.9 \%$. UHPLC analysis revealed no detectable hydrophobic impurities. Taking the remaining process steps into account, the overall recovery rate was $81.7 \pm 8.4 \%$.

\section{Conclusions}

Among the various methods we investigated for the purification of the RXP, only UHPLC was suitable for the removal of hydrophobic impurities. The RXP was captured and pre-purified using XAD- $16 \mathrm{~N}$ resin, resulting in the removal of salts as well as hydrophilic and weak hydrophobic impurities, combined with a $~ 14$-fold increase in product concentration and a recovery of $91.9 \pm 1.6 \%$. The analytical UHPLC method was optimized for intermediate purification, resulting in a resolution of $2.36 \pm 0.02$ and a recovery of $95.9 \pm 4.9 \%$. The quantity of the RXP purified using this method was small, but the high resolution will facilitate the purification of samples with a higher concentration; column scale-up is likely to result in an economically feasible process. The recovery after polishing was $92.7 \pm 7.9 \%$, representing an overall recovery rate of $81.7 \pm 8.4 \%$.

Supplementary Materials: The following are available online at https: / www.mdpi.com/article / 10.3390/separations8120241/s1, Table S1: Media composition of the adapted M9 medium used for RXP production in E. coli, Figure S1: Half-normal plot of the resolution screening, Figure S2: Normal plot of residuals of the resolution screening, Figure S3: Box-Cox plot for power transformation of the resolution screening, Figure S4: Predicted vs. actual plot of the resolution screening, Table S2: Analysis of variance of the resolution screening with coded factors $\mathrm{X}_{1}=$ temperature $\left({ }^{\circ} \mathrm{C}\right), \mathrm{X}_{2}=$ formic acid concentration $(\%)(v / v)$ and $X_{3}=$ gradient slope $\left(\% \mathrm{~min}^{-1}\right)$, Table S3: Fit statistics of the resolution screening, Table S4: Coefficients in terms of coded factors of the resolution screening with 
coded factors $\mathrm{X}_{1}=$ temperature $\left({ }^{\circ} \mathrm{C}\right), \mathrm{X}_{2}=$ formic acid concentration $(\%)(v / v)$ and $\mathrm{X}_{3}=$ gradient slope $\left(\% \min ^{-1}\right)$.

Author Contributions: Conceptualization, A.M.O.; Formal analysis, A.M.O.; Funding Acquisition, P.C.; Investigation, A.M.O. and S.R.; Methodology, A.M.O.; Project Administration, P.C.; Resources, P.C.; Supervision, D.G. and P.C.; Validation, A.M.O.; Visualization, A.M.O.; Writing-Original Draft, A.M.O.; Writing-Review and Editing, A.M.O., D.G., R.F. and P.C. All authors have read and agreed to the published version of the manuscript.

Funding: This research was funded by the LOEWE initiative (Landes-Offensive zur Entwicklung wissenschaftlich-ökonomischer Exzellenz) and the MegaSyn Research Cluster of the Hessian Ministry for Higher Education, Research and the Arts.

Data Availability Statement: All data of this study are contained in the manuscript or in the Supplementary Materials.

Acknowledgments: We would like to thank Richard M. Twyman for editing the manuscript.

Conflicts of Interest: The authors declare no conflict of interest. The funders had no role in the design of the study; in the collection, analyses, or interpretation of data; in the writing of the manuscript; or in the decision to publish the results.

\section{References}

1. Balibar, C.J.; Vaillancourt, F.H.; Walsh, C.T. Generation of D amino acid residues in assembly of arthrofactin by dual condensation/epimerization domains. Chem. Biol. 2005, 12, 1189-1200. [CrossRef]

2. Baltz, R.H.; Miao, V.; Wrigley, S.K. Natural products to drugs: Daptomycin and related lipopeptide antibiotics. Nat. Prod. Rep. 2005, 22, 717-741. [CrossRef]

3. Caboche, S.; Leclère, V.; Pupin, M.; Kucherov, G.; Jacques, P. Diversity of monomers in nonribosomal peptides: Towards the prediction of origin and biological activity. J. Bacteriol. 2010, 192, 5143-5150. [CrossRef] [PubMed]

4. Calcott, M.J.; Ackerley, D.F. Genetic manipulation of non-ribosomal peptide synthetases to generate novel bioactive peptide products. Biotechnol. Lett. 2014, 36, 2407-2416. [CrossRef]

5. Du, L.; Lou, L. PKS and NRPS release mechanisms. Nat. Prod. Rep. 2010, 27, 255-278. [CrossRef] [PubMed]

6. Felnagle, E.A.; Jackson, E.E.; Chan, Y.A.; Podevels, A.M.; Berti, A.D.; McMahon, M.D.; Thomas, M.G. Nonribosomal peptide synthetases involved in the production of medically relevant natural products. Mol. Pharm. 2008, 5, 191-211. [CrossRef] [PubMed]

7. Lawen, A. Biosynthesis of cyclosporins and other natural peptidyl prolyl cis/trans isomerase inhibitors. Biochim. Biophys. Acta 2015, 1850, 2111-2120. [CrossRef]

8. Sieber, S.A.; Marahiel, M.A. Molecular mechanisms underlying nonribosomal peptide synthesis: Approaches to new antibiotics. Chem. Rev. 2005, 105, 715-738. [CrossRef] [PubMed]

9. Grünewald, J.; Marahiel, M.A. Chemoenzymatic and template-directed synthesis of bioactive macrocyclic peptides. Microbiol. Mol. Biol. Rev. 2006, 70, 121-146. [CrossRef]

10. Cai, X.; Nowak, S.; Wesche, F.; Bischoff, I.; Kaiser, M.; Fürst, R.; Bode, H.B. Entomopathogenic bacteria use multiple mechanisms for bioactive peptide library design. Nat. Chem. 2017, 9, 379-386. [CrossRef]

11. Reimer, D.; Cowles, K.N.; Proschak, A.; Nollmann, F.I.; Dowling, A.J.; Kaiser, M.; ffrench-Constant, R.; Goodrich-Blair, H.; Bode, H.B. Rhabdopeptides as insect-specific virulence factors from entomopathogenic bacteria. Chembiochem 2013, 14, $1991-1997$. [CrossRef]

12. Abburi, K. Adsorption of phenol and p-chlorophenol from their single and bisolute aqueous solutions on Amberlite XAD-16 resin. J. Hazard. Mater. 2003, 105, 143-156. [CrossRef] [PubMed]

13. Agrawal, P.B.; Pandit, A.B. Isolation of $\alpha$-glucosidase from Saccharomyces cerevisiae: Cell disruption and adsorption. Biochem. Eng. J. 2003, 15, 37-45. [CrossRef]

14. Lee, J.C.; Park, H.R.; Park, D.J.; Lee, H.B.; Kim, Y.B.; Kim, C.J. Improved production of teicoplanin using adsorbent resin in fermentations. Lett. Appl. Microbiol. 2003, 37, 196-200. [CrossRef]

15. Lin, S.-H.; Juang, R.-S. Adsorption of phenol and its derivatives from water using synthetic resins and low-cost natural adsorbents: A review. J. Environ. Manag. 2009, 90, 1336-1349. [CrossRef]

16. Yang, S.A.; Pyle, D.L. The adsorption kinetics of cephalosporin-c on non-ionic polymeric macropore Amberlite XAD-16 resin. J. Chem. Technol. Biotechnol. 1999, 74, 216-220. [CrossRef]

17. Sandhu, A.K.; Gu, L. Adsorption/desorption characteristics and separation of anthocyanins from muscadine (Vitis rotundifolia) juice pomace by use of macroporous adsorbent resins. J. Agric. Food Chem. 2013, 61, 1441-1448. [CrossRef] [PubMed]

18. Lepane, V. Comparison of XAD resins for the isolation of humic substances from seawater. J. Chromatogr. A 1999, 845, 329-335. [CrossRef] 
19. Oestreich, A.M.; Suli, M.I.; Gerlach, D.; Fan, R.; Czermak, P. Media development and process parameter optimization using statistical experimental designs for the production of nonribosomal peptides in Escherichia coli. Electron. J. Biotechnol. 2021, 52, 85-92. [CrossRef]

20. Prasad, S.; Mandal, I.; Singh, S.; Paul, A.; Mandal, B.; Venkatramani, R.; Swaminathan, R. Near UV-Visible electronic absorption originating from charged amino acids in a monomeric protein. Chem. Sci. 2017, 8, 5416-5433. [CrossRef]

21. Saraiva, M.A. Interpretation of $\alpha$-synuclein UV absorption spectra in the peptide bond and the aromatic regions. J. Photochem. Photobiol. B 2020, 212, 112022. [CrossRef]

22. Hazra, C.; Samanta, T.; Mahalingam, V. A resonance energy transfer approach for the selective detection of aromatic amino acids. J. Mater. Chem. C 2014, 2, 10157-10163. [CrossRef]

23. Gheshlaghi, R.; Scharer, J.M.; Moo-Young, M.; Douglas, P.L. Application of statistical design for the optimization of amino acid separation by reverse-phase HPLC. Anal. Biochem. 2008, 383, 93-102. [CrossRef]

24. Huang, H.S.; Wu, J.R.; Chen, M.L. Reversed-phase high-performance liquid chromatography of amphoteric beta-lactam antibiotics: Effects of columns, ion-pairing reagents and mobile phase $\mathrm{pH}$ on their retention times. J. Chromatogr. 1991, 564, 195-203. [CrossRef]

25. Kaliszan, R.; Wiczling, P.; Markuszewski, M.J. pH gradient reversed-phase HPLC. Anal. Chem. 2004, 76, 749-760. [CrossRef]

26. Roses, M.; Canals, I.; Allemann, H.; Siigur, K.; Bosch, E. Retention of Ionizable Compounds on HPLC. 2. Effect of pH, Ionic Strength, and Mobile Phase Composition on the Retention of Weak Acids. Anal. Chem. 1996, 68, 4094-4100. [CrossRef] [PubMed]

27. Egeberg, P.K.; Alberts, J.J. Determination of hydrophobicity of NOM by RP-HPLC, and the effect of pH and ionic strength. Water Res. 2002, 4997-5004. [CrossRef]

28. Afsah-Hejri, L.; Jinap, S.; Arzandeh, S.; Mirhosseini, H. Optimization of HPLC conditions for quantitative analysis of aflatoxins in contaminated peanut. Food Control 2011, 22, 381-388. [CrossRef]

29. Issaq, H.J.; Fox, S.D.; Lindsey, K.; McConnell, J.H.; Weiss, D.E. Effect of Temperature on HPLC Separations Using C 1, C 4, C 8, and C 18 Alkyl Chain Bonded Silica Columns. J. Liq. Chromatogr. 1987, 10, 49-70. [CrossRef]

30. Martín, J.; Méndez, R.; Negro, A. Effect of Temperature on HPLC Separations of Penicillins. J. Liq. Chromatogr. 1988, 11, 1707-1716. [CrossRef]

31. Pappa-Louisi, A.; Nikitas, P.; Zisi, C.; Papachristos, K. Combined effect of temperature and organic modifier concentration on the retention under single mode gradient conditions in reversed-phase HPLC. J. Sep. Sci. 2008, 31, 2953-2961. [CrossRef]

32. Schellman, J.A. Temperature, stability, and the hydrophobic interaction. Biophys. J. 1997, 73, 2960-2964. [CrossRef]

33. Southall, N.T.; Dill, K.A.; Haymet, A.D.J. A View of the Hydrophobic Effect. J. Phys. Chem. B 2002, 106, 521-533. [CrossRef]

34. Bischof, J.C.; He, X. Thermal stability of proteins. Ann. N. Y. Acad. Sci. 2005, 1066, 12-33. [CrossRef]

35. Wijayanti, H.B.; Bansal, N.; Deeth, H.C. Stability of Whey Proteins during Thermal Processing: A Review. Compr. Rev. Food Sci. Food Saf. 2014, 13, 1235-1251. [CrossRef]

36. Peng, L.; Jayapalan, S.; Chankvetadze, B.; Farkas, T. Reversed-phase chiral HPLC and LC/MS analysis with tris (chloromethylphenylcarbamate) derivatives of cellulose and amylose as chiral stationary phases. J. Chromatogr. A 2010, 1217, 6942-6955. [CrossRef] [PubMed]

37. Carr, P.W.; Wang, X.; Stoll, D.R. Effect of pressure, particle size, and time on optimizing performance in liquid chromatography. Anal. Chem. 2009, 81, 5342-5353. [CrossRef] [PubMed]

38. Qin, Q.; Zhang, S.; Zhang, W.-G.; Zhang, Z.-B.; Xiong, Y.-J.; Guo, Z.-Y.; Fan, J.; Run-Zheng, S.; Finlow, D.; Yin, Y. The impact of silica gel pore and particle sizes on HPLC column efficiency and resolution for an immobilized, cyclodextrin-based, chiral stationary phase. J. Sep. Sci. 2010, 33, 2582-2589. [CrossRef] 